\title{
Factors affecting organic productions and its consumption approaches towards consumers: A case study of Punjab province
}

\begin{abstract}
Waqas Aslam ${ }^{1}$, Rana Shahzad Noor ${ }^{2}$, Saif Ullah ${ }^{1}$, Hong Chen ${ }^{1 *}$
${ }^{1}$ College of Economics and Management, Northeast Forestry University, Harbin 150040, China

${ }^{2}$ Department of Agriculture, Biological, Environment and Energy Engineering, College of Engineering, Northeast Agricultural University, Harbin 150030, China

Abstract

The growth of the organic market as a food trend has been the most debated issue, especially about concern for health and preservation of the environment. The evolution of this market has forced producers and companies to seek, through studies and surveys with the population, knowledge of the characteristics of consumers and the motivations that lead them to choose this segment. The attributes classified as intrinsic and extrinsic to the product are comprehensive and diverse, which greatly reinforce the purchase decision. However, the buyer's desire is strongly linked to economic factors since these products are more expensive than conventional ones. This study aimed to detect influencing factors of organic production and its consumption. A direct and structured descriptive research (survey) was carried out with 230 organic food consumers in Punjab, through the application of semi-structured questionnaires by applying Ordered Probit Model. This study results revealed that the consumption level of organic product depends on working status, consumer's income, family size, health conscious regarding its nutritional worth as a cognizant customer.
\end{abstract}

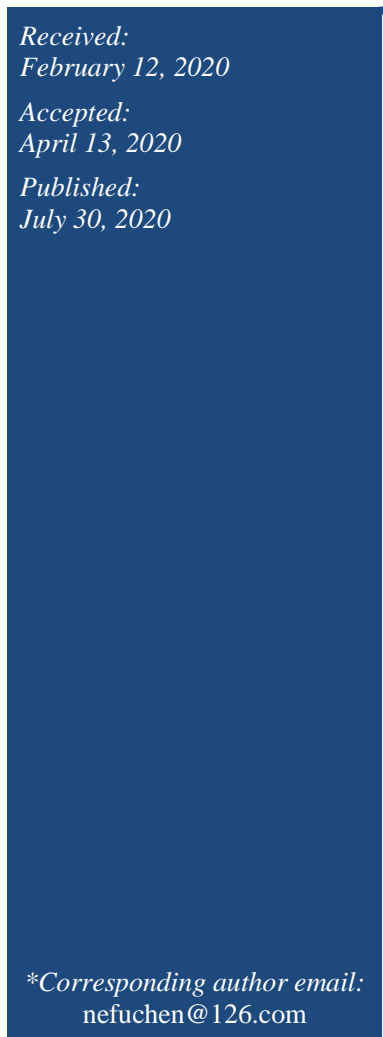

Keywords: Punjab, Ordered probit model, Organic product, Consumption trend

\section{How to cite this:}

Aslam W, Noor RS, Ullah S and Chen H, 2020. Factors affecting organic productions and its consumption approaches towards consumers: A case study of Punjab province. Asian J. Agric. Biol. 8(3): 274-280. DOI: https://doi.org/10.35495/ajab.2020.02.105

This is an Open Access article distributed under the terms of the Creative Commons Attribution 3.0 License. (https://creativecommons.org/licenses/by/3.0), which permits unrestricted use, distribution, and reproduction in any medium, provided the original work is properly cited.

\section{Introduction}

With intelligent and automatic technology, food production has started to change, and production has been increased due to diversity, cost advantages and mass production. Consumer habits have also been changed due to the increase and diversification of foodstuffs that people need. These foods commonly cause rapid consumption of people to consume many diseases, especially cancer and obesity (Mie et al.,
2017) Organic farming is a form of production in which no chemical, pesticide, fertilizer and plant regulators are applied during sowing, harvested, transported and stored, even reaches the consumers access (Hong, 2018). The main purpose of this form of agriculture is to produce all kinds of food and nutrients offered to the consumption of people, as well as production that does not harm human and nature in the production (Noor et al., 2019b).

The items that draw attention in the definition of the organic agriculture can be summarized; the use of 
chemical drugs, fertilizers and hormones is strictly prohibited. For plant nutrients, plant residues, animal fertilizers are used, plant alternation is carried out to protect nature and the environment and increase production and biological control is applied in pest and weed control (Noor et al., 2019a). Taking into consideration the eco system, it aims to direct consumer preferences with a production style that cares about plant, soil, animal and human health. Each stage of this form of agriculture is carried out based on the control of the certification bodies, and the products that produce successful production receive certification (Lernoud and Willer, 2019).

The organic agriculture is increasing and accepted in the world (Pacifico and Paris, 2016) in remote markets with the adoption of consumers who were consumed by themselves, individuals sold in nearby markets for the first time. Recently, changes in foodstuffs and its hazardous effects on health and environment provoked the consumers towards to Organic products (Hong, 2018). In addition, the concepts of healthy and balanced nutrition have become increasingly important due to the studies on the awareness of consumers. In this context, the issue of organic food consumption has gained an important place as a new quality center (Vitters $\varnothing$ and Tangeland, 2015).

An organic market segment has emerged that will enable people to access healthy and quality foods (Khan, 2016). In general, it is observed that the market for organic foods is expanding (Qasim et al., 2019). On the other hand, the proportion of consumers who regularly buy Organic products remains low (Stanton and Cook, 2019) .

The purpose of this research was to determine the factors affecting the Organic product consumption. Thus, it is thought that Organic products will be important in terms of forming marketing strategies and examining the size of the consumer.

\section{Material and Methods}

A survey was conducted at Rawalpindi division, Punjab province with the representative of organic farming (Farmers) to determine the factors affecting the organic agriculture production and recent trends in consumer behavior towards consumption of organic products. The number of questionnaires to be conducted using the proportional sampling method has been determined. In this method, the sample size was determined by using $95 \%$ confidence interval and $5 \%$ margin of error. The equation used in determining the number of surveys is shown (Taherdoost, 2017).

$n=\frac{N^{*} P^{*}(1-p)}{(N-1)^{*} \sigma_{P}^{2}+P^{*}(1-P)}$

Where;

n: Sample size,

$\mathrm{N}$ : Number of consumers (households),

$\sigma_{\mathrm{p}}^{2}$ : Variance,

r: Deviation from the mean (5\%),

$Z_{\alpha / 2}$ : scale value (1.96),

$\mathrm{p}$ : Share of households consuming organic products in total $(82 \%)$. In the study, $\mathrm{p}$ and $\mathrm{q}$ values were determined with 100 preliminary surveys.

$$
\begin{aligned}
Q_{p}^{2} & =\left(\frac{r}{z_{\alpha / 2}}\right)^{2} \ldots \ldots \ldots \ldots \ldots \ldots \ldots \ldots \ldots \ldots \ldots \ldots \ldots \ldots \ldots \ldots \ldots \\
Q_{p}^{2} & =\left(\frac{0.05}{1.96}\right)^{2}=(0.0255)^{2}=0.000651 \\
& =\frac{394684 * 0.82 * 0.18}{(394683 * 0.000651)+(0.82 * 0.18)} \cong 227
\end{aligned}
$$

Considering that there may be deficiencies or mistakes in the surveys to be carried out, it was found appropriate to carry out additional surveys up to $1 \%$ of the sample size. In this context, a survey was conducted with $227+(227 \times 0.01)=230$ households .

The organic product Consumption levels were acquired to determine the factors affecting the Organic product and Consumption status of the consumers in Punjab. The Organic product Consumption status of each consumer is classified as low, medium and high. Those who consume little or not at all (low) are coded into 0 , sometimes those who consume (medium) 1 and 2 for those who consume continuously (high) are divided into three categories. Thus, Ordered Probit Model was used in order to determine the factors affecting the Organic product Consumption level of the consumers.

Ordered Probit Model (Güney and Giraldo, 2019, Arumugam, 2017) is the most suitable model for the data set in which the dependent variable receives sequential natural number values. 
Ordered Model where the dependent variable is encoded as 0 low, 1 medium and 2 high for each awareness, attitude and behavior is expressed as follows.

$y_{i}^{*}=\beta^{\prime} X_{i}+\varepsilon_{i}, \varepsilon_{i}: F\left(\varepsilon_{i} i \mid \theta\right)$,

$E\left(\varepsilon_{i} \mid X_{i}\right)=0$, and $\operatorname{Var}\left(\varepsilon_{i} \mid X_{i}\right)=1 \ldots$ (3)

$y^{*}$ when dependent variable cannot be observed, $\beta$ vector of estimated coefficients, $x$ is a vector of the explanatory variables, vector of error terms (considered to be normally distributed as $\varepsilon \sim \mathrm{N}[0,1]$ ), and $\mathrm{F}$ means any distribution that can be considered in the research.

$$
\begin{gathered}
y_{i}=0 \quad \text { if } y_{i} \leq \mu_{0}, \\
y_{i}=1 \quad \text { if } \mu_{0}<y_{i} \leq \mu_{1},
\end{gathered}
$$

$y_{i}=1 \quad$ if $\mu_{1}<y_{i} \leq \mu_{2}$,

While $\mu_{j}$, represents breakpoints or threshold values, $y$ is the value observed for $y^{*}$ breakpoints vary according to the individual characteristics of the participants.

The above observation mechanism was the result of the hidden bounded dependent variable shown below. Since consumers with similar socio-economic characteristics and environmental awareness, attitudes or behaviors will have similar breakpoints, breakpoints are expected to show normal distribution (Irandoust, 2016, Rezai et al., 2015).

If $\varepsilon$ is assumed to be normally distributed for observations, the possibility of choosing a specific order by a participant can be expressed as follows (McFadden and Huffman, 2017).

$\operatorname{rob}\left[y_{i}=j\right]=\operatorname{Prob}\left[y_{i}^{*}\right.$ is in the $j$ th range $]=$ $\Phi\left(\mu_{j}-\beta^{\prime} X_{i}\right)-\Phi\left(\mu_{j-1}-\beta^{\prime} X_{i}\right)$. (5)

$$
j=0,1,2 \text {. }
$$

$\Phi$ When it is the normal cumulative density function (cdf), $\mu \mathrm{j}$ and $\mu \mathrm{j}+1$ represent upper and lower threshold values for category $j$, respectively. Considering that $\mu-1=-\infty$ and $\mu 0=0$, this probability is specifically as follows.

$$
\begin{aligned}
& \operatorname{Prob}\left[y_{i}=0\right]=\Phi\left(\mu_{j}-\beta^{\prime} X_{i}\right) \\
& \operatorname{Prob}\left[y_{i}=1\right]=\Phi\left(\mu_{1}-\beta^{\prime} X_{i}\right)-\Phi\left(-\beta^{\prime} X_{i}\right) \\
& \operatorname{Prob}\left[y_{i}=2\right]=\Phi\left(\mu_{2}-\beta^{\prime} X_{i}\right)-\Phi\left(\mu_{1}-\beta^{\prime} X_{i}\right)---(6)
\end{aligned}
$$

$$
\begin{aligned}
& \log L=\sum_{i=1}^{N} \sum_{j=0}^{2} y_{i j} \log \left(\Phi\left(\mu_{j}-\beta^{\prime} X_{i}\right)-\Phi\left(\mu_{j-1}-\beta^{\prime} X_{i}\right)\right) \\
& =\sum^{N} \quad y_{i=0} \log \left(\Phi\left(-\beta^{\prime} X_{i}\right)\right)+ \\
& \sum^{N} \quad y_{i=1} \log \left(\Phi\left(\mu_{1}-\beta^{\prime} X_{i}\right)-\right. \\
& \left.\Phi\left(-\beta^{\prime} X_{i}\right)\right)+\sum^{N} \quad y_{i=1} \log \left(\Phi\left(\mu_{1}-\beta^{\prime} X_{i}\right)-\right. \\
& \left.\Phi\left(-\beta^{\prime} X_{i}\right)\right)+\sum^{N} \quad y_{i=2} \log \left(\Phi\left(\mu_{2}-\beta^{\prime} X_{i}\right)-\right. \\
& \left.\Phi\left(-\beta^{\prime} X_{i}\right)\right) \ldots \ldots .(7)
\end{aligned}
$$

\section{Results and Discussion}

In the research, interviews were made with 230 consumers in Punjab province and the statistical summary and explanations of the variables examined are given in Table 1.

The average age of consumers participating in the study was determined to be $38.66 \%$ married and $65 \%$ male. (Zeeshan et al., 2017) stated that the average age of 272 individuals interviewed in Punjab for 2017 was 35.04 years, $76 \%$ of them were married and $54 \%$ of them were male, as a marital status. According to (Khan et al., 2019), they found that the average age of 600 people in the same region is 42.01 years, $53 \%$ in terms of marital status are married and $50 \%$ are male in terms of gender. It was determined that the education levels of the participants were generally secondary.

(Khan and Jan, 2018) determined that the number of individuals living in the households is 3.25 while $23.4 \%$ attended higher secondary school and $42 \%$ of the surveyed individuals have a business profession, $30 \%$ are students, $8 \%$ are unemployed and $20 \%$ are housewives. It was determined that the households have an average monthly income of 291 \$ and sometimes pay attention to a balanced and healthy diet. In addition, whether the consumers participating in the study are conscious consumers were examined in 4 categories according to the 5-point Likert scale (none: 1, sometimes: 2, half: 3 , generally: 4 and always: 5).

The degree of sensitivity of the consumer to items such as making a list before shopping, looking at the label while shopping, examining the use of environmentally friendly products or packaging, paying attention to the expiration date and purchasing receipts after shopping. 2. To what extent the consumers pay attention to the warranty or the brand. 3. The questions about the importance of the consumer when purchasing the product, 4. 
Table-1. Statistical summary and explanation of variable.

\begin{tabular}{|c|c|c|c|}
\hline Variables & Descriptions & Average & $\begin{array}{c}\text { Sd. } \\
\text { Error }\end{array}$ \\
\hline Age & $\begin{array}{l}\text { Age of the } \\
\text { surveyed } \\
\text { individual }\end{array}$ & 38.008 & 12.730 \\
\hline Gender & $\begin{array}{c}\text { Male: } 1, \\
\text { Female: } 0\end{array}$ & 0.652 & 0.031 \\
\hline marital status & $\begin{array}{l}\text { Married: } 1, \\
\text { Single: } 0\end{array}$ & 0.660 & 0.031 \\
\hline Education status & $\begin{array}{l}\text { Literate: } 1 \text {, } \\
\text { Primary: } 2 \text {, } \\
\text { Secondary: } 3 \text {, } \\
\text { University: } 4 \text {, } \\
\text { Graduate: } 5\end{array}$ & 3.304 & 0.931 \\
\hline Working status & $\begin{array}{l}\text { Yes: } 1, \\
\text { No: } 0 \\
\end{array}$ & 0.613 & 0.488 \\
\hline Family size & $\begin{array}{l}\text { The number of } \\
\text { individuals in } \\
\text { the family }\end{array}$ & 4.257 & 1.845 \\
\hline Revenue & $\begin{array}{l}\text { Household } \\
\text { income } \\
\text { (Months / \$) }\end{array}$ & 3309.348 & 1927.442 \\
\hline $\begin{array}{l}\text { Balanced and } \\
\text { healthy nutritional } \\
\text { status }\end{array}$ & $\begin{array}{l}\text { No: } 0 \text {, } \\
\text { Sometimes: } 1 \text {, } \\
\text { Yes: } 2,\end{array}$ & 1.074 & 0.787 \\
\hline $\begin{array}{l}\text { Conscious } \\
\text { consumer status }\end{array}$ & $\begin{array}{l}\text { No: } 0 \text {, } \\
\text { Sometimes: } 1 \text {, } \\
\text { Yes: } 2 \text {, }\end{array}$ & 1.465 & 0.658 \\
\hline $\begin{array}{l}\text { Price research } \\
\text { status }\end{array}$ & Yes: 1, No: 0 & 0.778 & 0.416 \\
\hline $\begin{array}{l}\text { Quality research } \\
\text { status }\end{array}$ & Yes: 1, No: 0 & 0.857 & 0.351 \\
\hline $\begin{array}{l}\text { Being } \\
\text { knowledgeable } \\
\text { about organic } \\
\text { product }\end{array}$ & $\begin{array}{l}\text { No: } 0 \text {, } \\
\text { Sometimes: } 1 \text {, } \\
\text { Yes: } 2 \text {, }\end{array}$ & 1.352 & 0.713 \\
\hline $\begin{array}{l}\text { Checking the } \\
\text { organic certificate } \\
\text { of the product }\end{array}$ & $\begin{array}{l}\text { No: } 0 \text {, } \\
\text { Sometimes: } 1 \text {, } \\
\text { Yes: } 2,\end{array}$ & 0.935 & 0.825 \\
\hline
\end{tabular}

The extent to which they know the consumer rights as a consumer were asked. Here, 1 and 2 answers are analyzed considering zero, 3 answers as one and 4 and 5 answers as two coefficients. As a result, it was determined that consumers generally have shopping consciousness. $77.8 \%$ of consumers do price research and $85.7 \%$ do quality research. In order to determine the level of knowledge of consumers about the product, 4 questions were asked on the 5-point Likert scale (none: 1 , sometimes: 2 , half: 3 , generally: 4 and always: 5).

1. At what stage organic products should not be used from production to consumption, chemical substance and pesticide hormone should not be used,

2. At which stage of organic production, certification process,

3. Level of knowledge about organic product label in organic products and

4. To what extent traditional or village type products it is organic. (None: 5 and always: 1) These four questions were analyzed by evaluating them as $1,2,3$ (0), 4 (1) and 5 (2). In addition, while it is seen that the consumers are partially informed about the organic product, the rate of checking the organic certificate of the product is low. (Bhatti, 2018) list the sources of information consumers use about organic products as internet, television, magazine-newspaper and salespeople. Results In the study by using Ordered Probit Analysis, the organic product consumption status of consumers in Punjab was divided into three categories according to low, medium and high rank, and they were analyzed in the Ordered Probit Model and the results are given in Table 2.

Looking at the results of the analysis, it is seen that the signs of the parameters are generally in the expected direction. Considering the variables that are statistically significant, the fact that consumers are willing to increases the consumption of organic products and this variable is shown at $1 \%$ significance level. Working status decreases the low organic product consumption rate by about $20 \%$ and the moderate consumption rate by about $11 \%$ while increasing the high level of consumption by about $31 \%$. It can be stated that the fact that people take part in the work life has led to the emergence of such a result, as it enables them to be conscious and knowledgeable about related problems. It has been determined that the increase in the number of individuals in households increases the level of organic product consumption and this variable is statistically significant (5\%). It has been determined that those who consume low and medium level organic products reduce their households by about $2 \%$ and increase the rate of those who consume high levels by about $4 \%$.

In this case, the increase in the number of individuals in the household have more earning capacity and they can afford organic product willing to pay more for healthier foods. 
Waqas Aslam et al.

Table-2. Results of ordered probit analysis by organic product consumption status

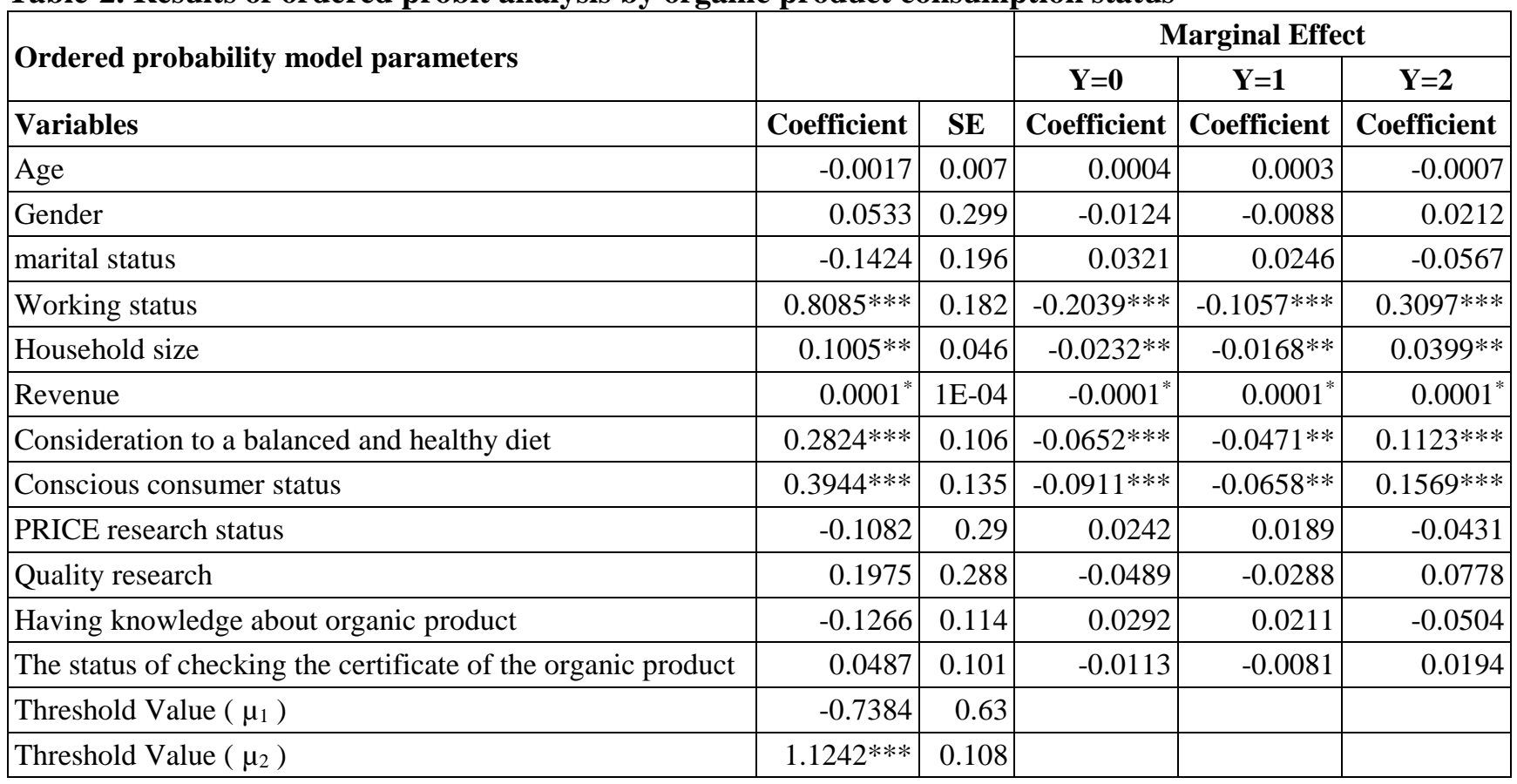

$* 10 \%$ significance level, $* * 5 \%$ significance level, $* * * 1 \%$ significance level

Monthly income is highly and positively significant for consumption of organic product which is shown $10 \%$. Looking at the marginal effects for income, it is seen that the impact rate is quite low. It is an expected result that income will positively affect consumption and be an increasing factor especially for organic product consumption. In the case of low income, the organic product consumption rate decreased by $0.01 \%$ in the group consuming low organic products, while it increased by $0.01 \%$ in the groups consuming medium and high organic products. (Hong, 2018) stated that the increase in the income and education level of the household head has a positive effect on organic vegetable consumption (Moser, 2016) the prices of organic products are 3-5 times higher than that of conventional products, causing higher demand for organic products for families with high income. In addition (Omar et al., 2017) found that an increase in the income of the family in the household by one unit increased the amount of organic product consumption of the household 1.2 times. (Jouzi et al., 2017) have determined that the rate of those who think that organic production should increase in shape of price premium of organic products is $40 \%$, the reduction in cost rate as $10 \%$. The issue of the negative effects of non-organic products on health is an issue raised in many platforms and created awareness in the society. It is expected that the importance of organic product consumption is clearly seen in a balanced and healthy diet, (de-Magistris and Gracia, 2016) who carried out a study that supports this result, found that consumers, who desire a protective, healthy and balanced diet, turn to organic products by paying more prices when the consumers' payment demands are taken into consideration. Despite the increase in organic foods in markets in recent years, consumers' perceptions of trust have become more skeptical for the labeling system and similar factors such as the quality of organic foods. It was determined that individuals expressing that they are a conscious consumers increased their level of organic product consumption positively and statistically significance at a level of $1 \%$. It has been found that while the rate of those who consume low organic products by $9 \%$ and those who consume medium level organic products by $7 \%$, they increase the rate of those who consume high level organic products by about $16 \%$. (Yin et al., 2016) evaluated consumer information and food labeling schemes have an important role in increasing organic food consumption. (Asif et al., 2018) stated that the increase in the objective and subjective knowledge levels of consumers regarding organic food and more experience and awareness, reflects a more positive attitude towards organic foods. (Rahman and Noor, 2016) explored ways to promote organic production to the producer, which has difficulty in keeping up with 
growing consumer demand in Bangladesh. (Aschemann-Witzel and Zielke, 2017) showed that advertisements aimed at highlighting the environmental awareness of a product within the scope of promotion activities did not affect the conscious consumers, but more to the consumers who did not know about it.

\section{Conclusion}

In the study, ordered Probit model was applied to determine the factors affecting organic product consumption according to consumer. The results of the study showed that, 5 of the 13 factors were statistically significant and these factors were the household head, household size, household income, awareness to nutritional health and consumer vision. The studied model analyzed that as the income in the households increase, the organic product consumption amount of the group consuming low organic products decreases, and the organic product consumption amount of the households consuming medium and high-level organic products increases. As a result, factors such as household income and the number of households that are indirectly influential on this income and the individual's dealing with an income generating activity were found effective in increasing the tendency of consumers towards organic products.

\section{Acknowledgment}

Authors acknowledge the support of College of Economics and Management, Northeast Agricultural University, Harbin China.

Disclaimer: None.

Conflict of Interest: None.

Source of Funding: None.

\section{References}

Arumugam S, 2017. Willingness to pay a premium for produce at direct marketing outlets: an ordered probit analysis. SAARC J. Agric. 15: 19-30.

Aschemann-Witzel J and Zielke S, 2017. Can't buy me green? A review of consumer perceptions of and behavior toward the price of organic food. J. Consum. Aff. 51: 211-251.

Asif M, Xuhui W, Nasiri A and Ayyub S, 2018. Determinant factors influencing organic food purchase intention and the moderating role of awareness: A comparative analysis. Food Qual. Pref. 63: 144-150.

Bhatti A, 2018. Sales Promotion and Price Discount Effect on Consumer Purchase Intention with the Moderating Role of Social Media in Pakistan. Int. J. Bus. Manage. 3: 50-58.

de-Magistris T and Gracia A, 2016. Consumers' willingness-to-pay for sustainable food products: the case of organically and locally grown almonds in Spain. J. Clean. Prod. 118: 97-104.

Güney OI and Giraldo L, 2019. Consumers' attitudes and willingness to pay for organic eggs. Brit. F. J. 22: 678-692.

Hong WAC, 2018. Comparative Profitability Analysis of Conventional and Organic Vegetable Farming in Khyber Pakhtunkhwa and Azad Jammu Kahsmir, Pakistan. Methodol. 9.

Irandoust M, 2016. Modelling consumers'demand for organic food products: the swedish experience. Int. J. Food Agric. Econ. 4(3): 77-89.

Jouzi Z, Azadi H, Taheri F, Zarafshani K, Gebrehiwot K, Van Passel S and Lebailly P, 2017. Organic farming and small-scale farmers: Main opportunities and challenges. Ecol. Econ. 132: 144-154.

Khan J, Jan A, Lim KH, Shah SA, Khanal AR and Ali $G$, 2019. Household's perception and their willingness to pay for pesticides-free fruits in Khyber Pakhtunkhwa (KP) province of Pakistan: A double-bounded dichotomous choice contingent valuation study. Sarhad. J. Agric. 35: 266-1271.

Khan $\mathbf{J}$ and Jan AU, 2018. Factors influencing households' willingness to pay for pesticides-free fresh apple in District Peshawar, Khyber Pakhtunkhwa (KP) Pakistan. Sarhad. J. Agric. 34 :599-605.

Khan S, 2016. A study of Buyers' and Sellers' Perception of Organic Foods in Pakistan: Towards a More Effective Marketing Mix. Third International Conference on Marketing Kuala Lumpur Malaysia. p. 9.

Lernoud J and Willer H, 2019. Organic Agriculture Worldwide: Key results from the FiBL survey on organic agriculture worldwide. Part 2: Crop data.

McFadden JR and Huffman WE, 2017. Willingnessto-pay for natural, organic, and conventional foods: The effects of information and meaningful labels. Food Poli. 68: 214-232. 
Mie A, Andersen HR, Gunnarsson S, Kahl J, KesseGuyot E, Rembiałkowska E, Quaglio G and Grandjean P, 2017. Human health implications of organic food and organic agriculture: a comprehensive review. Environ. Health. 16: 111.

Moser AK, 2016. Consumers' purchasing decisions regarding environmentally friendly products: An empirical analysis of German consumers. J. Retail. Consum. Services. 31: 389-397.

Noor RS, Wang Z, Umair M, Yaseen M, Ameen M, Rehman SU, Khan MU, Imran M, Ahmed W and Sun Y, 2019b. Interactive Effects of Grafting Techniques and Scion-Rootstocks Combinations on Vegetative Growth, Yield and Quality of Cucumber (Cucumis sativus L.). Agron. 9: 288.

Noor RS, Wang Z, Umair M, Ameen M, Imran M and Sun Y, 2019a. Performance Evaluation of a Water Seed Drill. Sust. 11: 1-13.

Omar NA, Nazri MA, Osman LH and Ahmad MS, 2017. The effect of demographic factors on consumer intention to purchase organic products in the Klang Valley: An empirical study. Geog. Malay. J. Soc. Space. 12: 68-82.

Pacifico D and Paris R, 2016. Effect of organic potato farming on human and environmental health and benefits from new plant breeding techniques. Is It Only a Matter of Public Acceptance? Sustainability. 8(10): 1054.

Qasim H, Yan L, Guo R, Saeed A and Ashraf BN, 2019. The Defining Role of Environmental SelfIdentity among Consumption Values and Behavioral Intention to Consume Organic Food. Int. J. Environ. Res. Public Health. 16: 1106.

Rahman KM and Noor NAM, 2016. Exploring organic food purchase intention in Bangladesh: an evaluation by using the theory of planned behavior. Int. Busi. Manage. 10: 4292-4300.
Rezai G, Mohamed Z and Shamsudin MN, 2015. Can halal be sustainable? Study on Malaysian consumers' perspective. J. Food Prod. Market. 21: 654-666.

Stanton JV and Cook LA, 2019. Product knowledge and information processing of organic foods. J. Cons. Market. 36: 240-252.

Taherdoost H, 2017. Determining sample size; how to calculate survey sample size. Int. J. of Econ. Manage. Syst. 2: 1-3..

Vitters $\varnothing \mathrm{G}$ and Tangeland T, 2015. The role of consumers in transitions towards sustainable food consumption. The case of organic food in Norway. J. Clean. Product. 92: 91-99.

Yin S, Chen M, Chen Y, Xu Y, Zou Z and Wang Y, 2016. Consumer trust in organic milk of different brands: the role of Chinese organic label. Brit. Food J. 118: 1769-1782.

Zeeshan M, Shah H, Durrani Y, Ayub M, Jan Z and Shah M, 2017. A questionnaire-based survey on food safety knowledge during food-handling and food preparation practices among university students. J. Clin. Nutr. Diet. 3: 1-8.

\section{Contribution of Authors}

Aslam W: Data collection, data analysis, investigation and manuscript writing

Noor RS: Conceived idea, design \& development of the experiment, data collection, data analysis and manuscript writing

Ullah S: Contributed to perform formal analysis of data of this manuscript

Chen H: Investigated, reviewed and supervised the whole research experimental study and the manuscript writing 